\title{
Selenium supplementation inhibits lipopolysaccharide-induced endometritis by decreasing the cholesterol content of lipid rafts
}

\author{
Yi-fan Zhao ${ }^{1, *}$, Shuo Zhu ${ }^{1, *}$, Ying-fang Guo ${ }^{1, *}$, Xin-ying Wang ${ }^{1}$, Wei-jing Sun ${ }^{1}$, Jun- \\ kun Ma', Hao-han Y $\mathbf{u}^{1}$ and Meng-yao Guo ${ }^{1}$ \\ ${ }^{1}$ College of Veterinary Medicine, Huazhong Agricultural University, Wuhan 430070, People's Republic of China \\ *These authors contributed equally to this work
}

Correspondence to: Meng-yao Guo, email: gmy1985@163.com

Keywords: endometritis; selenium; TLR4; cholesterol; lipid rafts

Received: May 30, $2017 \quad$ Accepted: November 20, 2017

Published: January 06, 2018

Copyright: Zhao et al. This is an open-access article distributed under the terms of the Creative Commons Attribution License 3.0 (CC BY $3.0)$, which permits unrestricted use, distribution, and reproduction in any medium, provided the original author and source are credited.

\section{ABSTRACT}

We investigated the protective effects of selenium (Se) against lipopolysaccharide (LPS)-induced endometritis in mice. Female mice were fed Se-containing diets prior to being challenged with an intrauterine injection of LPS. Histopathological changes, expression of Toll-like receptor 4 (TLR4)-related signaling molecules and inflammatory cytokines, as well as tissue and lipid raft-associated cholesterol levels were measured in ex-vivo and in vitro experiments conducted with uterine tissues and cells. Results showed that Se reversed LPS-induced changes in uterine histopathology and decreased myeloperoxidase activity as well as levels of the pro-inflammatory cytokines TNF-a and IL-1 $\beta$ in excised uteri. Se supplementation also hampered LPS-induced TLR4 signaling by attenuating NF-KB and IRF3 expression, and promoted the degradation of cholesterol in both uterine tissues and lipid rafts from cultured endometrial cells. In these cells, Se also inhibited LPS-induced production of inflammatory cytokines, including TNF- $a$, IL-1 $\beta$, and IL-6, and blocked expression of NF-KB and IRF3. These protective effects of Se were abolished by knocking down the cholesterol-sensing liver $x$ receptor alpha (LxRa), which resulted in downregulation of the cholesterol efflux regulatory protein ABCA1. We conclude that the anti-inflammatory actions of Se against LPS-induced endometritis are associated with upregulation of the LxRaABCA1 pathway, leading to lipid raft destruction through cholesterol-depletion, which impedes the translocation of TLR4 to lipid rafts and blocks the ensuing inflammatory cascade.

\section{INTRODUCTION}

Endometritis is a reproductive disorder characterized by purulent or mucous inflammation of uterine tissue that leads to a decrease in productivity and fertility in cows and other animals [1]. This condition is usually caused by post-parturition infection, with Escherichia coli being one of the main pathogens [2,3]. Lipopolysaccharide (LPS), a major component of E. coli 's outer membrane, mediates the activation of the TLR4 signaling pathway [4]. After binding LPS, TLR4 is recruited to lipid rafts [5] and activates a series of downstream signaling molecules leading to the production of inflammatory mediators $[6,7]$. Thus, analysis of the biogenesis and structural composition of lipid rafts may aid in the identification of cellular pathogens, and help deter the progression of inflammation.

Selenium (Se), one of the nutritionally necessary trace elements for a large range of species, exerts a variety of biological effects including immune protection [8] and alleviation of tissue injuries $[9,10]$, and regulates muscle metabolism and apoptosis [11, 12], brain function and neuropathology [13], and reproduction [14]. Accordingly, Se deficiency can lead to pathological conditions, including reproductive disorders and inflammatory diseases. Research has shown that Se can attenuate the occurrence and extent of inflammation by negatively modulating TLR4 and TLR4-related signaling molecules, thus reducing the expression of proinflammatory cytokines including TNF- $\alpha$, IL-1 $\beta$, and IL-6 [1]. The biological 
functions of Se are mediated by selenoproteins, 25 of which have been identified until now [15]. Among these, some Selenoproteins has been shown to regulate the release of inflammatory cytokines and to influence the reproductive health of humans and animals [16].

Lipid rafts are cholesterol-rich microdomains formed on cells' outer leaflets of the plasma membrane $[7,17]$, they act as TLR4 acceptors, providing a platform for receptor-ligand recognition and complex formation necessary for activation of the TLR 4 signaling cascade [18]. While some studies demonstrated a function for Se in reducing cholesterol levels [19, 20], whether Se-mediated anti-inflammatory actions are related to alterations in the metabolism of cholesterol in lipid rafts has not been elucidated.

In this study, we tested the hypothesis that Se reduces lipid raft formation by decreasing their cholesterol content, and consequently hinders TLR4 signaling to protect uterine tissue against inflammatory lesions induced by LPS stimulation in a mouse model of endometritis.

\section{RESULTS}

\section{Ex vivo experiments}

\section{Se concentration in uterine tissues and blood}

To characterize the absorption of Se by uterine tissues and its bioavailability in blood, female mice were fed diets containing low $(0.015 \mathrm{mg} / \mathrm{kg}$; low-Se group), normal $(0.15 \mathrm{mg} / \mathrm{kg}$; normal-Se group), or high (1.5 $\mathrm{mg} / \mathrm{kg}$; high-Se group) Se concentrations. 90 days later, Se contents were estimated in excised uteri and blood samples. Results showed that the concentration of Se in both uterine tissue and blood increased dose-dependently with the Se concentration provided in the feed (Figure 1). Meanwhile, challenging the mice with LPS via intrauterine injection did not affect tissue or blood Se contents.

\section{LPS-induced histopathological changes in uterine tissues}

To evaluate whether Se supplementation can reduce or prevent the histopathological changes induced by LPS on mice uteri, mice were fed diets containing various $\mathrm{Se}$ concentrations (as described above) before being injected intrauterinelly with LPS $(0.05 \mathrm{mg} / \mathrm{ml})$ or normal saline. $24 \mathrm{~h}$ later, uterine tissues were collected, fixed, and subjected to H\&E staining. As shown in Figure 2, salineinjected, control samples presented a normal structure, and no pathological changes were observed under a light microscope whether the selenium concentration of the tissue was high (Figure 2A), normal (Figure 2B) or low (Figure 2C). In contrast, in animals challenged with LPS the three layers of the uterus were seriously damaged, and a clear boundary between them could not be defined.
Histopathological changes in these samples included inflammation, shedding, congestion, and swelling of the endometrium, and disappearance of acinar structures. Interestingly, these lesions were markedly attenuated in the high-Se group (Figure 2D), compared with the normalSe group (Figure 2E) and the low-Se group (Figure 2F) of mice, which evidenced the most severe tissue damage. These results demonstrate that Se had a protective effect against LPS-induced lesions in the mouse uterus.

\section{Se protects against LPS-induced uterine cell apoptosis}

To assess whether Se supplementation ameliorates LPS-induced apoptosis, TUNEL staining was performed on uterine tissue sections from mice fed low, normal, or high Se diets. Results showed that TUNEL staining was almost completely absent in samples without LPS stimulation (Figure 3A-3C). In contrast, tissues from LPS-treated mice showed various degrees of TUNEL staining, and this effect was dose-dependently attenuated by Se. The results displayed the LPS induced many apoptotic cells. Along with the progress of the testing time, compared with Group N-LPS, the apoptotic cells was significantly decreased in Group H-LPS, but it was increased significantly in Group L-LPS. These results were shown in Figure 3D-3F.

\section{Se attenuates the increases in myeloperoxidase deficiency (MPO) activity and inflammatory cytokines induced by LPS}

MPO activity reflects the degree of tissue infiltration of neutrophils and is used as a correlate of the severity of inflammation. As shown in Figure 4A, MPO activity in the mouse uterus was significantly enhanced by LPS, and this stimulation was gradually reversed by increasing tissue concentrations of Se. Next, to investigate the basis of the inhibitory effect of Se on LPS-induced uterine inflammation, changes in the expression of the proinflammatory cytokines TNF- $\alpha$ and IL-1 $\beta$ were analyzed by qPCR. As expected, LPS treatment increased TNF- $\alpha$ and IL-1 $\beta$ mRNA, while Se dose-dependently attenuated the production of both mRNAs (Figure 4B4C). Compared with Group N-LPS, the MPO activity and inflammatory cytokines expressions were significantly decreased in Group H-LPS, but it was increased significantly in Group L-LPS.

\section{Se inhibits LPS-mediated TLR4 signaling}

TLR4 is the main receptor of LPS and its activation a leading trigger of inflammation. To investigate whether the anti-inflammatory effect exerted by Se on LPSexposed uterine tissues is mediated by changes in TLR4 and/or its downstream signaling molecules, tissue levels of 
TLR4, NF-кB p65, and IRF3 were measured by western blot. As shown in Figure 5, LPS elicited a significant increase in all these proteins, and these changes were reversed by Se supplementation. Compared with N-LPS, the phosphorylation level of NF- $\mathrm{B}$ p65, and IRF3 were significantly reduced in H-LPS, and significantly increased in L-LPS (Figure 5).

\section{Se decreases LPS-induced lipid raft formation}

Translocation of TLR4 into lipid rafts facilitates the onset of LPS-induced inflammatory responses. To evaluate whether Se affects lipid raft formation, these structures were detected in uterine tissues by immunofluorescence staining. As shown in Figure 6, LPS increased lipid raft formation and

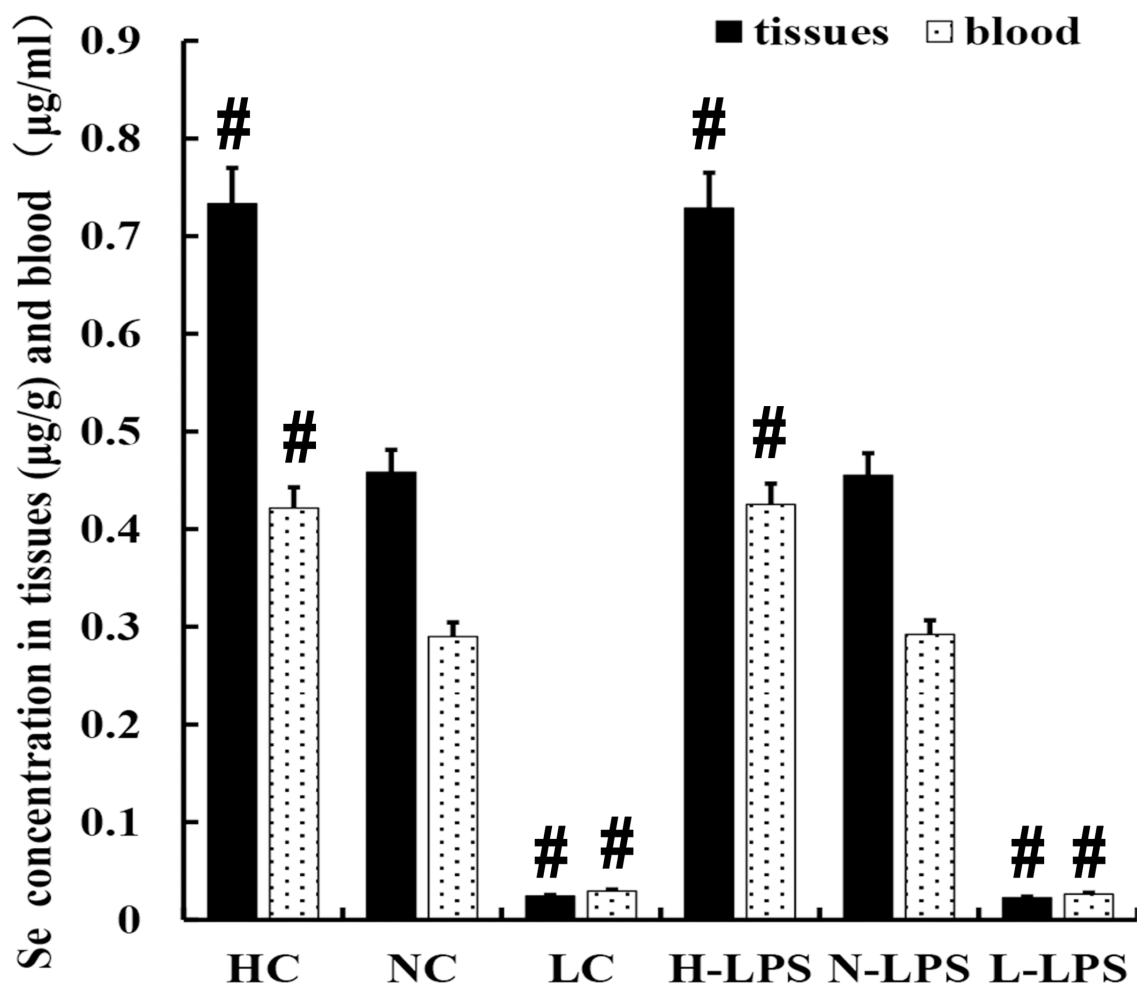

Figure 1: Se concentration in uterine tissues and blood. Mice were divided in three groups and fed a diet containing high (H), normal (N), or low (L) Se concentrations. 90 days later, each group was further divided in two sub-groups, one receiving LPS stimulation (H-LPS; N-LPS; L-LPS) and the other normal saline (HC; NC; LC). Se concentration was measured 24 h after LPS administration. Data are means $\pm \operatorname{SEM}(n=10) .{ }^{\#} p<0.05$, compared with the NC and N-LPS groups.
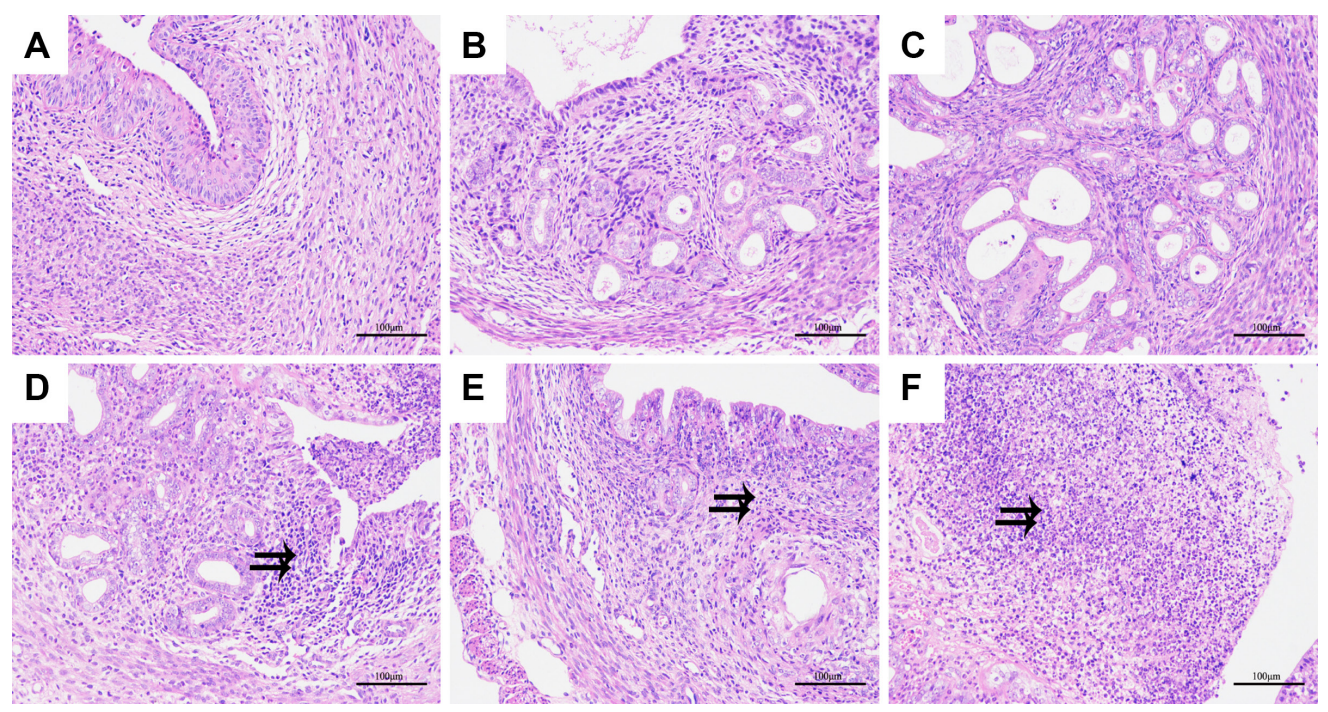

Figure 2: Histopathological staining of uterine tissue sections. Representative H\&E images of uterine tissues from mice in the high-Se (A), normal-Se (B), low-Se (C), LPS + high-Se (D), LPS + normal-Se (E), and LPS + low-Se (F) groups. 
this effect was inhibited in tissues from Se-supplemented mice. Compared with the N-LPS, the lipid raft formation was significantly increased in the L-LPS and significantly decreased in the H-LPS. Compared with the NG, the mRNA and protein expression levels of $\mathrm{CaM}$ were significantly increased in $\mathrm{HG}$ and significantly reduced in LG
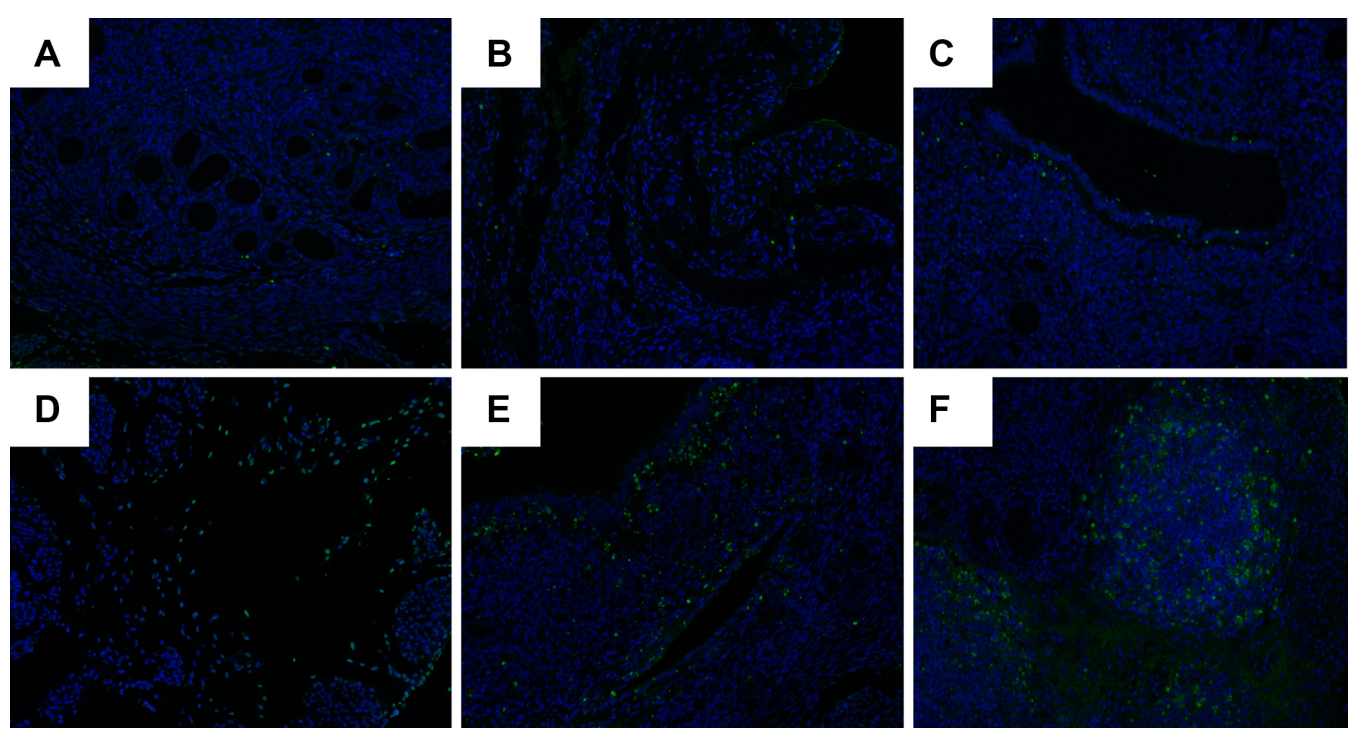

Figure 3: TUNEL staining in uterine tissue sections. Representative images of uterine tissues from mice in the high-Se (A), normal-Se (B), low-Se (C), LPS + high-Se (D), LPS + normal-Se (E), and LPS + low-Se (F) groups.
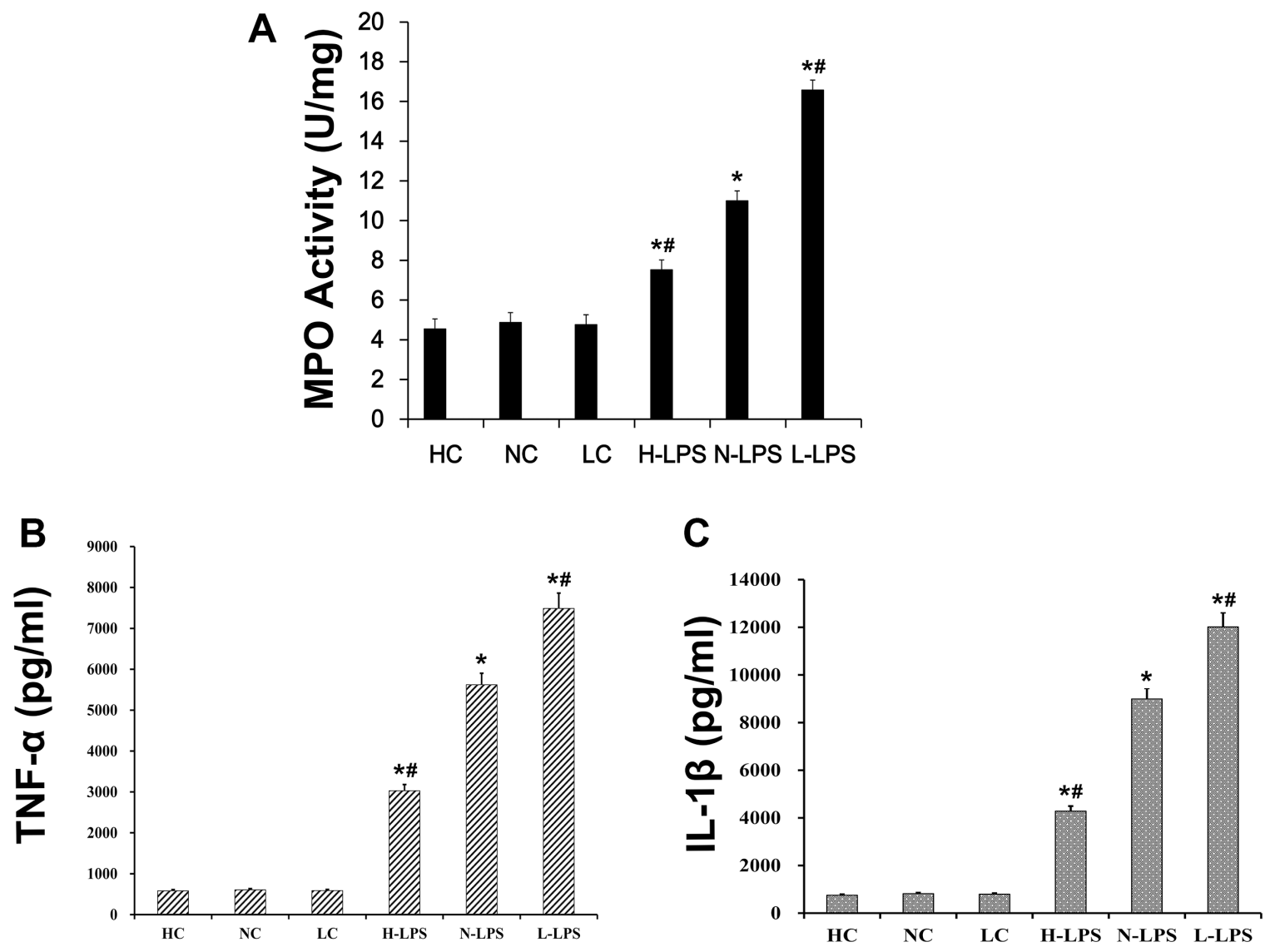

Figure 4: Se attenuates LPS-induced MPO activity and TNF- $\alpha$ and IL-1 $\beta$ production. (A) Effects of Se on MPO activity in LPS-stimulated uterine tissues. (B) TNF- $\alpha$ protein levels in uterine tissues. (C) IL-1 $\beta$ protein levels in uterine tissues. ELISA was used to measure TNF- $\alpha$ and IL-1 $\beta$. Data are means \pm SEM $(n=10) .{ }^{*} p<0.05$, compared with the N-LPS group; ${ }^{*} p<0.05$, LPS vs. non-treated within each main group. 


\section{Se decreases uterine cholesterol content}

Based on the reduction of lipid raft formation elicited by $\mathrm{Se}$ in uterine tissues exposed to LPS, cholesterol levels were measured in isolated lipid rafts extracted from control and LPS-challenged uteri. Attesting to the proposed cholesterol lowering properties of $\mathrm{Se}$, the highest concentration of cholesterol was measured in the low-Se group, while reduced cholesterol levels were detected in the normal-Se and high-Se groups (Figure 7).

\section{In vitro experiments}

\section{Identification of endometrial cells and effect of Se on cell viability}

Mouse endometrial epithelial cells adhere to culture plates 4-5 hours after seeding, and generate a monolayer $\sim 24 \mathrm{~h}$ later. These cells can be identified by immunolabeling with keratin 18 (Figure $8 \mathrm{~A}$ ). To evaluate the potential cytotoxicity of Se on endometrial

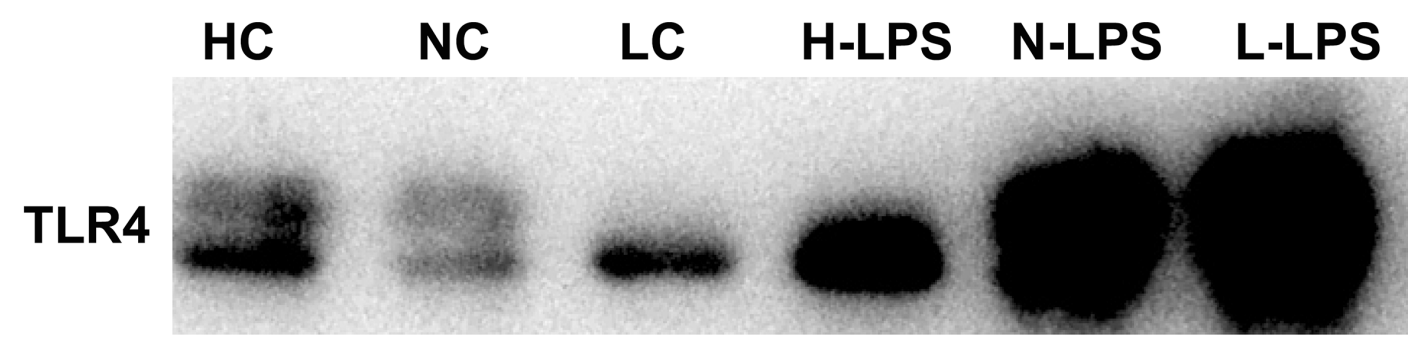

p65

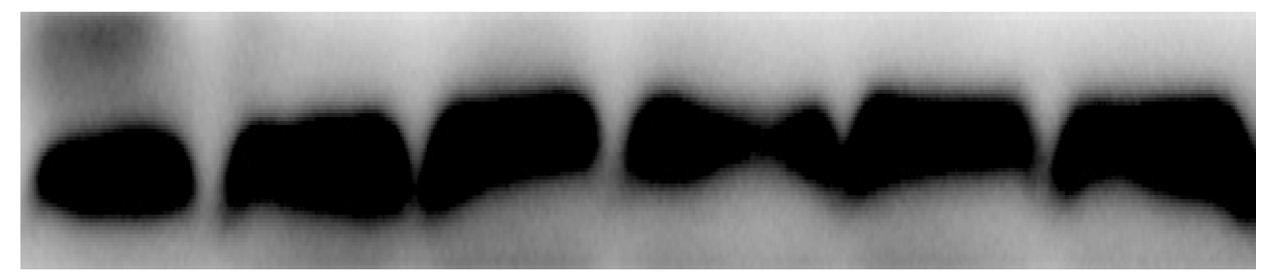

p-p65

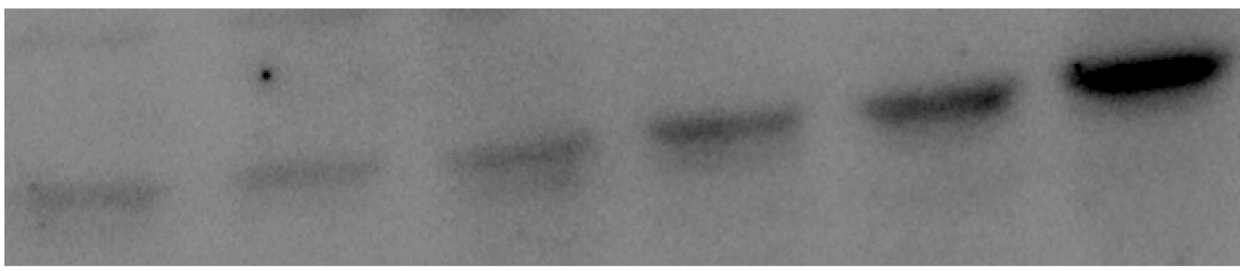

IRF3

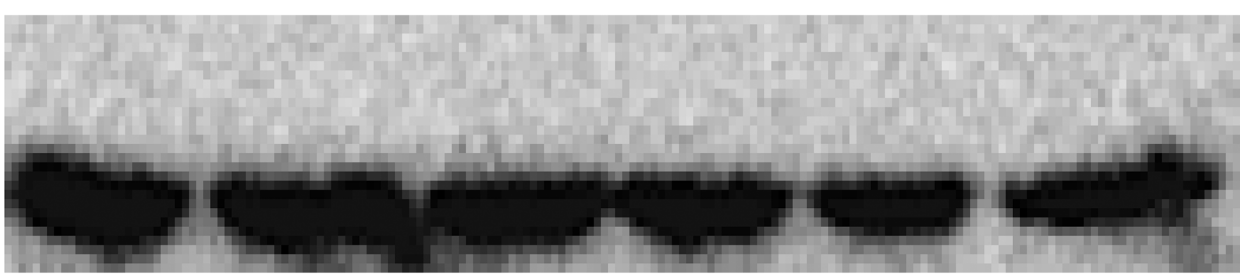

p-IRF3

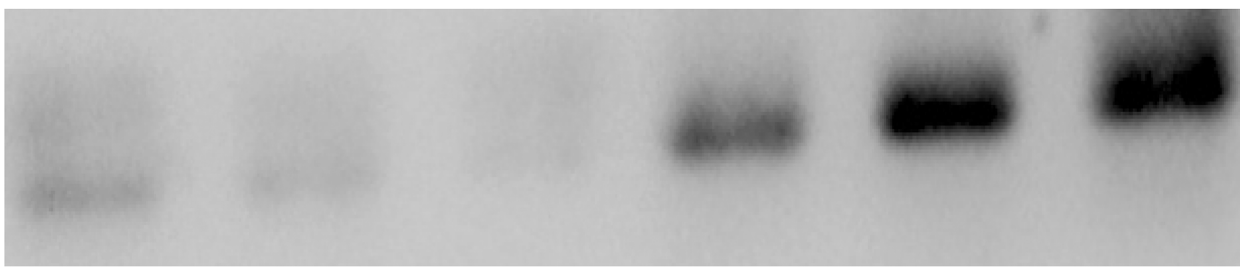

\section{$\beta$-actin}

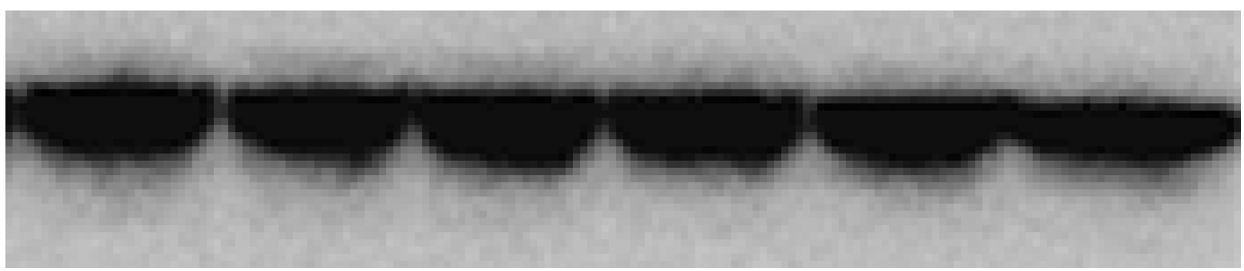

Figure 5: Se inhibits LPS-induced TLR4, NF-KB, and IRF3 expression. Protein expression levels were measured in uterine tissues by western blot. $\beta$-actin was used as a loading control. 
cell cultures, cells were treated with $0,2.5$, or $5 \mu \mathrm{M} \mathrm{Se}$ and the MTT assay was carried out. As shown in Figure $8 \mathrm{~B}$, cell viability was not affected by the different Se concentrations, indicating absence of significant cytotoxicity.

\section{Se inhibits inflammatory cytokine secretion by endometrial cells}

mRNA and protein levels of TNF- $\alpha$, IL-1 $\beta$, and IL-6 were measured by qPCR and western blot, respectively, in cells challenged with LPS. Exposure of cells to Se inhibited production of these cytokines in a dosedependent way (Figure 9).

\section{Se decreases TLR4 translocation to lipid rafts in cell}

To assess the effect of Se on TLR4, NF- $\kappa$ B, and IRF3 localization to lipid rafts, lipid rafts were extracted from cells and subjected to western blot. As shown in Figure 10, little TLR4 was present in lipid rafts from nonLPS treated cells, regardless of previous Se exposure. In contrast, TLR4, NF- $\kappa \mathrm{B}$, and IRF3 protein levels were increased in lipid rafts from LPS-treated cells, and these changes were dose-dependently counteracted by Se.

\section{Se reduces cholesterol content in cultured cells}

In support of evidence that Se can promote cellular consumption of cholesterol, total cholesterol content of LPS-stimulated cells cultured in medium containing a high Se concentration $(5 \mu \mathrm{M})$ was lower than in cells supplemented with $2.5 \mu \mathrm{M}$ Se or without Se supplementation (Figure 11A). Meanwhile, in non-LPSchallenged cells, the addition of Se to the culture medium had little or no effect on cellular cholesterol content.

\section{Se upregulates the expression of $\operatorname{LxR} \alpha$ and ABCA1}

The liver $\mathrm{X}$ receptor (LxR) is a nuclear transcription factor that binds oxysterols and plays a key role in maintaining cholesterol balance, in part by regulating cholesterol efflux via upregulation of ABCA1. To assess whether the cholesterol-lowering effects of $\mathrm{Se}$ are associated with changes in $\mathrm{LXR} \alpha$ and/or ABCA1 levels, a luciferase reporter gene assay and western blot were respectively used to measure the expression of these proteins. Results showed that the expression of both the $\operatorname{LxR} \alpha$ luciferase reporter gene and ABCA1 increased with the amount of Se supplied to the cells (Figure 11B-11C).
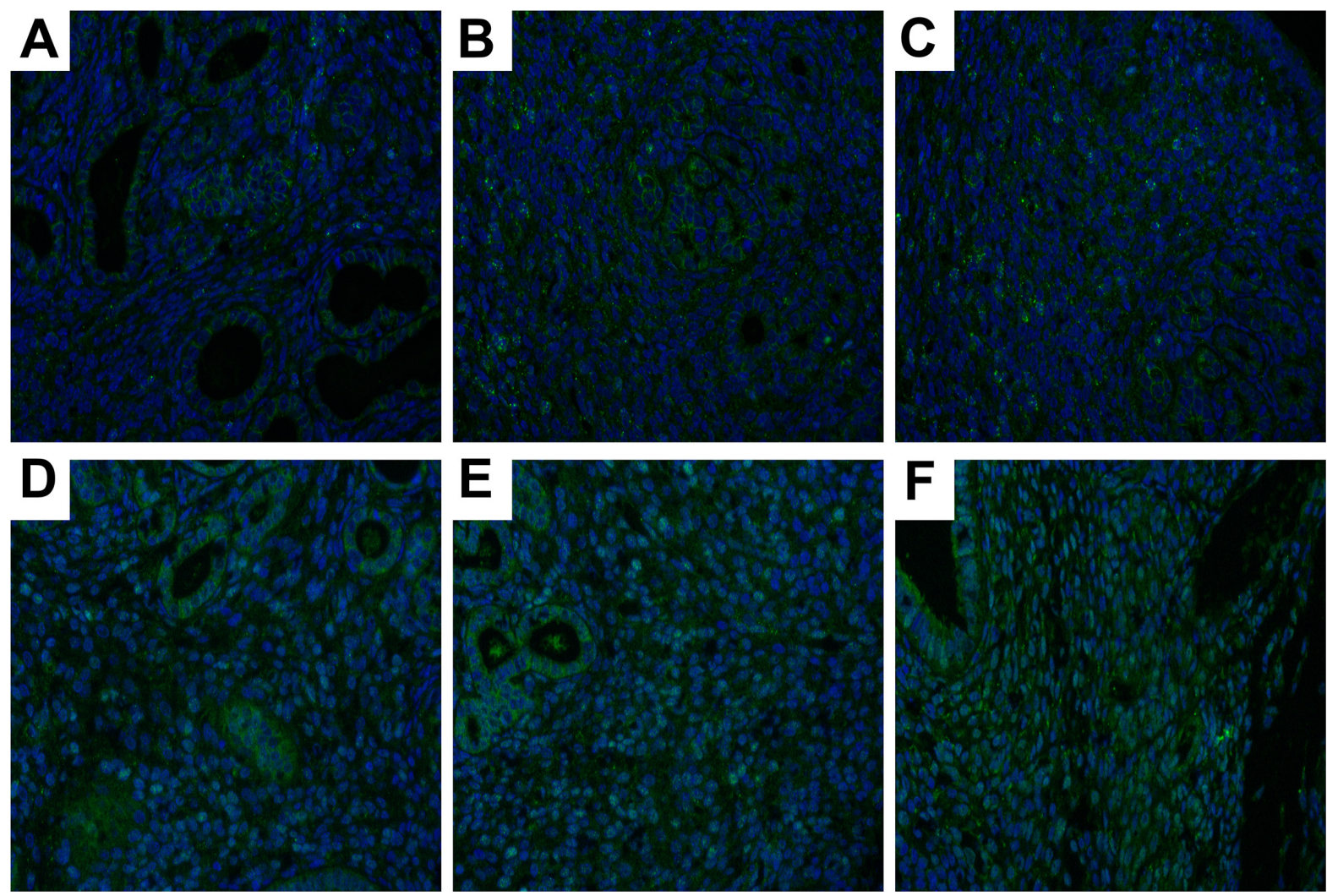

Figure 6: Se inhibits LPS-stimulated lipid raft formation. Uterine tissues were fixed and then subjected to immunofluorescence staining Lipid rafts are stained green. LPS increased lipid raft formation and this effect was inhibited in tissues from Se-supplemented mice. (A) High-Se, (B) Normal-Se, (C) Low-Se, (D) LPS + High-Se, (E) LPS + normal-Se, (F) LPS + low-Se. 


\section{Knockdown of $\operatorname{LxR} \alpha$ abrogates the inhibitory effects of Se on LPS-induced inflammation}

To investigate whether the anti-inflammatory actions of Se depend on $\mathrm{LxR} \alpha$ activation, $\mathrm{LxR} \alpha$ silencing was achieved using a specific siRNA, the treatment of LPS among all the groups. As shown in Figure 12A, the expression of both $\mathrm{LxR} \alpha$ and ABCA1 was effectively suppressed by siRNA-mediated knockdown. In addition, LxR $\alpha$ silencing also reversed the decrease in cholesterol content and inflammatory cytokines elicited by Se in LPStreated cells (Figure 12B-12E) and negated the attenuating effect of Se on the expression of TLR4, NF-kB, and IRF3 following exposure to LPS (Figure 13).

\section{DISCUSSION}

The occurrence of endometritis, an inflammatory condition that affects the lining of the uterus, is associated with the exacerbated release of inflammatory factors [1]. Several studies suggested that Se has anti-inflammatory effects [15], and may also promote cholesterol degradation [19]. In light of this, the present study was designed to test the hypothesis that Se confers protection against LPSinduced endometritis in mice.
In vivo administration of LPS caused shedding of the endometrial epithelium, congestion and swelling of endometrial layers, disappearance of uterine acinar structures, and extensive apoptosis. Notably, dietary supplementation with Se protected the uterus from these lesions. We also found that LPS stimulation increased tissue MPO activity, indicative of neutrophil infiltration during the inflammatory reaction, and this effect was significantly suppressed in tissues from mice fed Secontaining diets.

Upon pathogen invasion, macrophages in the affected organ recognize the pathogen and become activated, secreting several inflammatory cytokines, such as TNF- $\alpha$, IL- 6 , and IL- $1 \beta$, to mount the body's defense. Studies have shown that the above cytokines also play an important role in endometritis [5, 21]. Our ex vivo and in vitro results suggest that Se supplementation dosedependently reduces the production of TNF- $\alpha$, IL- 6 , and IL-1 $\beta$ in uterine tissues and cells of LPS-stimulated mice.

Lipid rafts are dynamic, cholesterol and sphingomyelin-rich, microdomains on the cell membrane that play a fundamental role in signal transduction $[17$, 18]. Following binding and activation by LPS, TLR4 is translocated to lipid rafts and mediates downstream activation of NF- $\mathrm{kB}$ and IRF3 [22], which regulate the

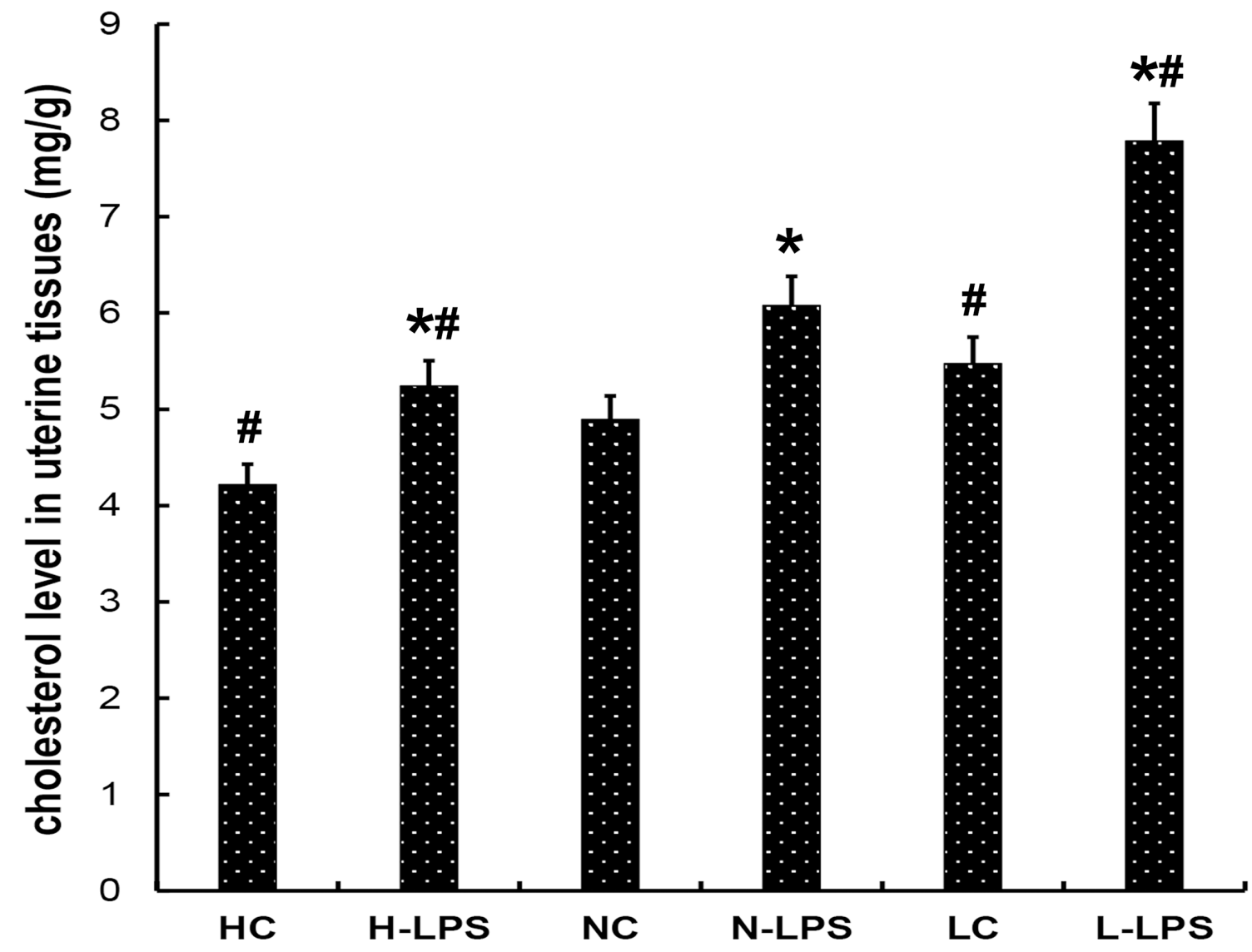

Figure 7: Se reduces LPS-induced cholesterol accumulation in uterine tissues. Cholesterol contents were determined using a Cholesterol Quantitation Kit and measured with a microplate reader. Values are means \pm SEM. ${ }^{*} p<0.05$, compared with the NC and the N-LPS groups. " $p<0.05$, compared with the non-treated group. 
transcription of genes encoding, respectively, various proinflammatory cytokines and anti-inflammatory molecules [23]. Protein expression analyses suggested that the beneficial actions of Se result from attenuation of TLR4 signaling by inhibiting its translocation to lipid rafts and decreasing the expression of the effector proteins NF- $\mathrm{BB}$ and IRF3.

Our experiments further showed that cholesterol degradation was increased by Se supplementation. Cholesterol is an important component of lipid rafts, and its degradation causes disintegration of these structures, destabilizing TLR4 positioning platform and rendering it unable to interact with its molecular partners. As a result, the activation of TLR4 downstream signal pathway is prevented and the inflammatory response is suppressed.

The nuclear receptor LxR controls cholesterol metabolism in cells and tissues by regulating a range of proteins associated with the production and degradation of cholesterol [24], including the cholesterol-exporting protein ABCA1 [25]. Considering the cholesterol-
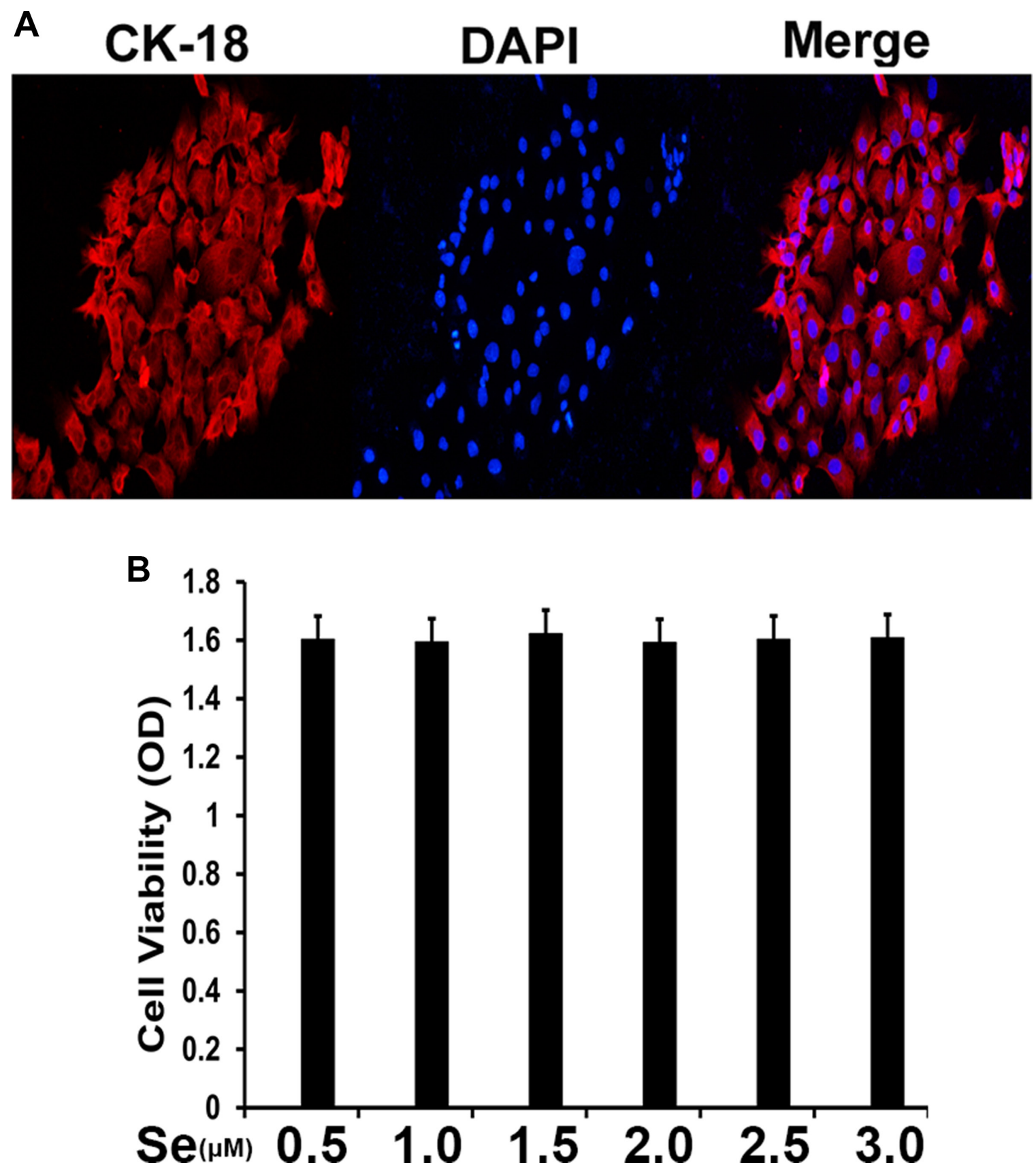

Figure 8: Identification of endometrial epithelial cells and viability assay. (A) Endometrial epithelial cells were labeled with an anti-keratin 18 antibody and visualized using confocal laser microscopy to confirm integrity. Red color indicates keratin 18 labeling; nuclei are stained blue. (B) Cell viability, as determined by the MTT assay, was not affected by addition of Se to the culture medium. Values are presented as means \pm SEM. 

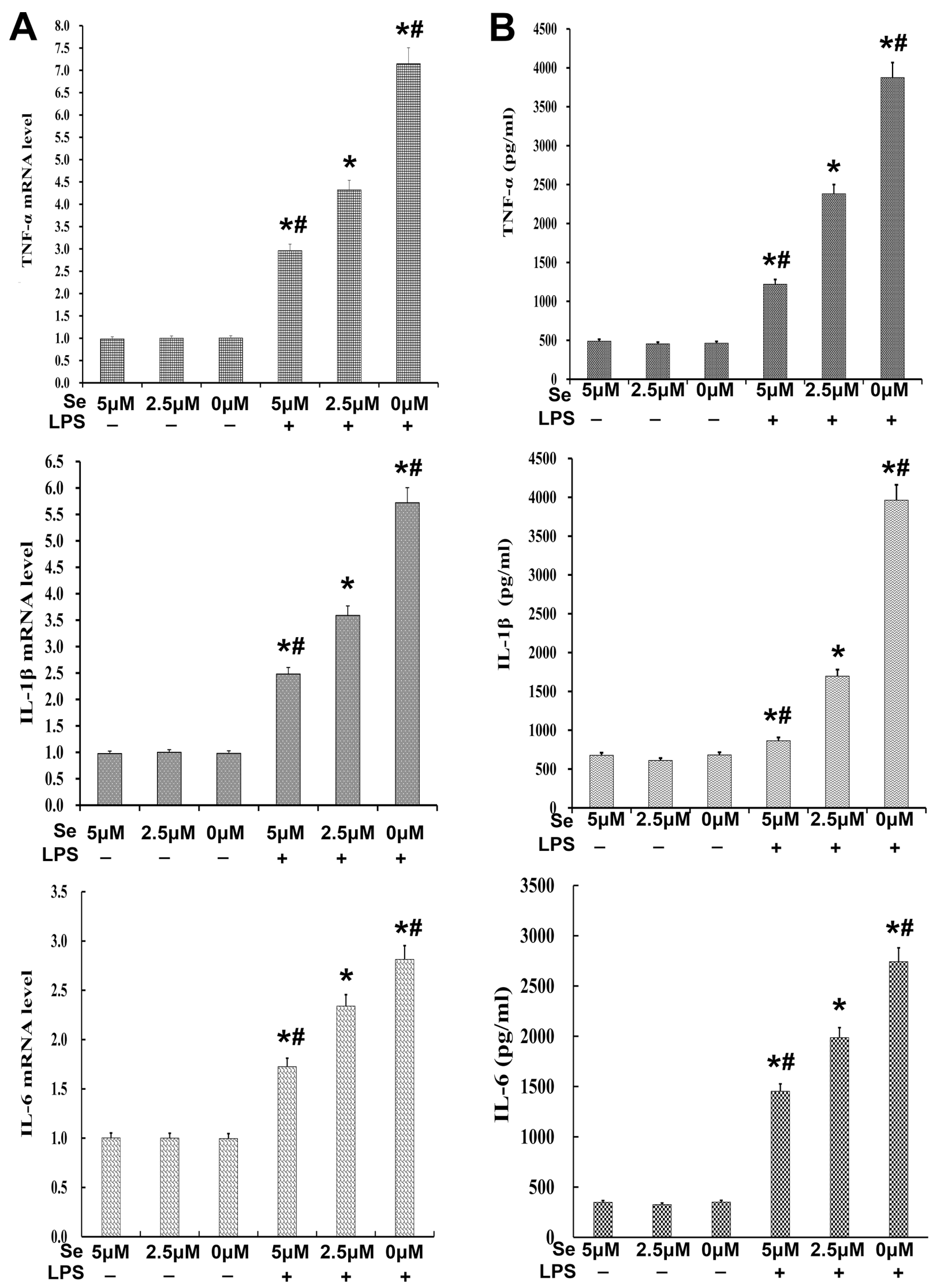

Figure 9: Se inhibits the LPS-induced expression of inflammatory cytokines in endometrial epithelial cells. (A) Changes in TNF- $\alpha$, IL-1 $\beta$, and IL- 6 mRNA levels measured by qPCR. (B) TNF- $\alpha$, IL-1 $\beta$, and IL-6 protein levels detected by ELISA. ${ }^{~} p<0.05$, compared with the LPS $+2.5 \mu \mathrm{M}$ Se group, ${ }^{*} p<0.05$, compared with the non-stimulated group. 
degrading effects of Se supplementation, its influence on $\operatorname{LxR} \alpha$ expression was also tested. Experiments on endometrial cells indicated that Se activates the $\operatorname{LxR} \alpha$ ABCA1 pathway to increase cholesterol efflux and reduce cholesterol content on the cell membrane, thus negatively regulating the formation of lipid rafts.

In conclusion, the present study shows that $\mathrm{Se}$ supplementation in mice blocked TLR4 translocation to lipid rafts, reduced lipid raft-associated and total cellular cholesterol, decreased the release of inflammatory cytokines in uterine tissues and cells, and attenuated histopathological features of LPS-induced endometritis. The anti-inflammatory effect of Se seems to be associated with upregulation of the LxR $\alpha$-ABCA1 pathway and increased metabolism of cholesterol. As a result, both the formation of lipid rafts and the transfer of TLR4 to lipid

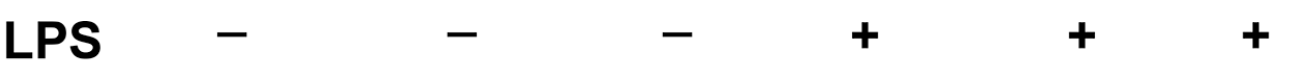

\section{Se $5 \mu \mathrm{M} \quad 2.5 \mu \mathrm{M} \quad 0 \mu \mathrm{M} \quad 5 \mu \mathrm{M} \quad 2.5 \mu \mathrm{M} \quad 0 \mu \mathrm{M}$}

TLR4

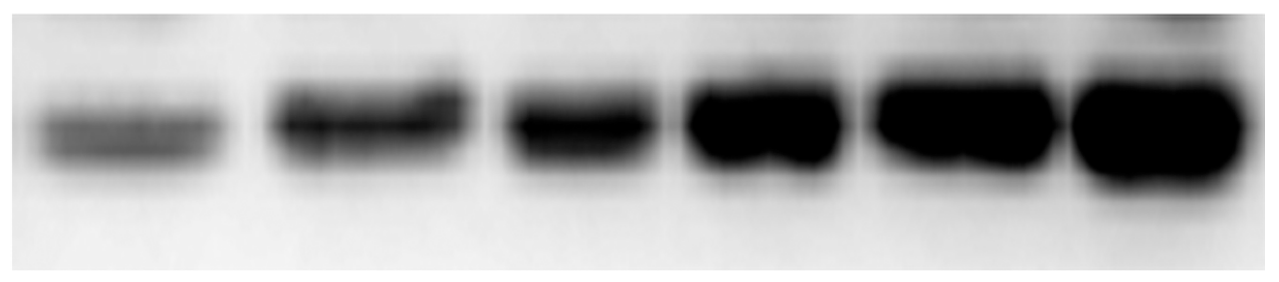

p65

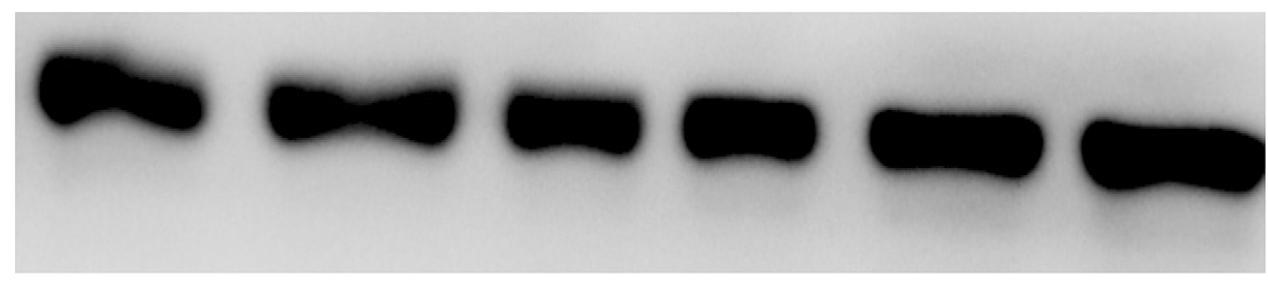

p-p65

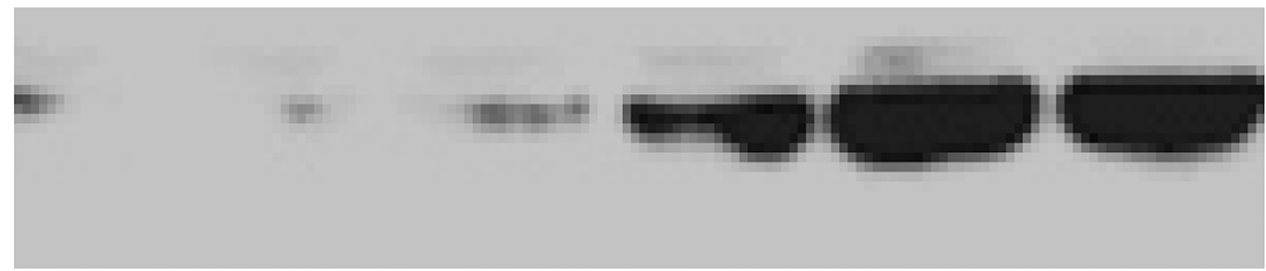

IRF3

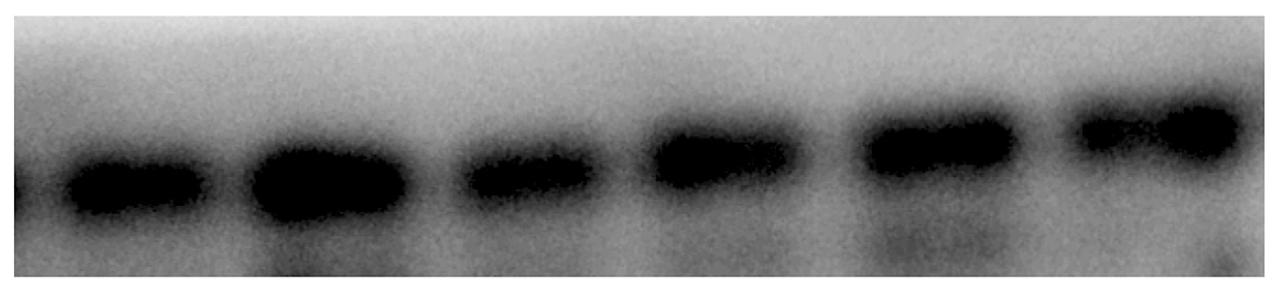

p-IRF3
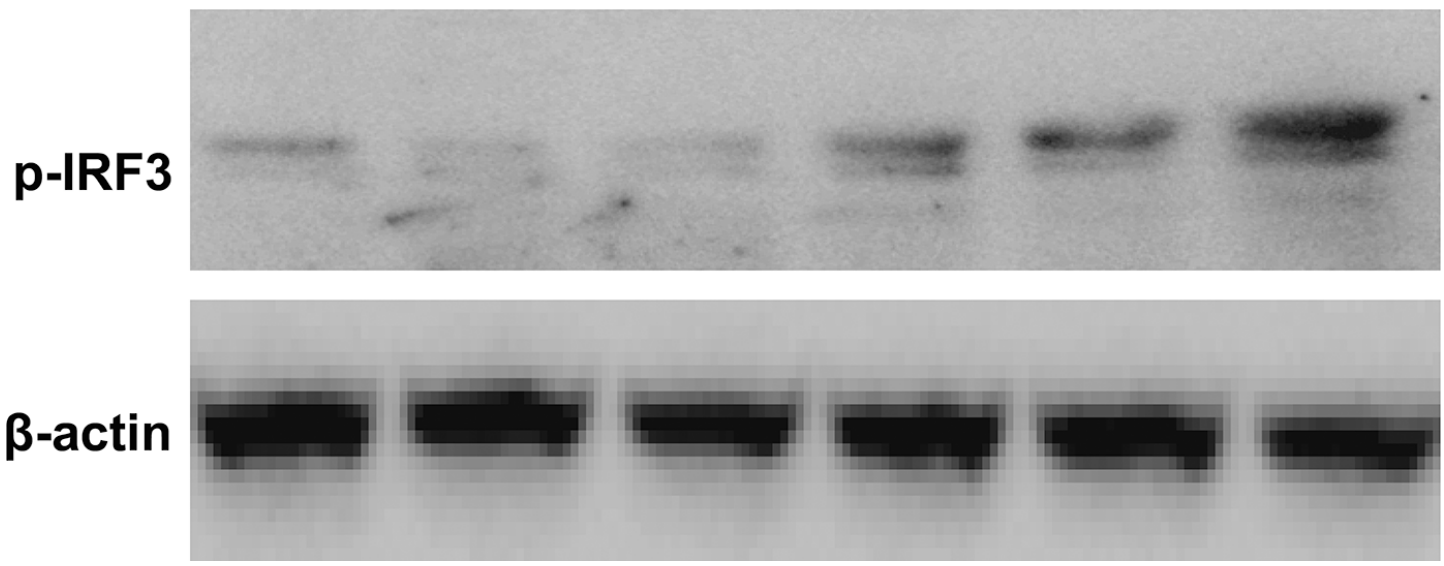

Figure 10: Se reduces TLR4, NF-кB, and IRF3 expression with lipid rafts in cell. After extraction of lipid rafts from endometrial cells, protein levels were analyzed by western blot using specific antibodies. $\beta$-actin was used as a loading control. 
rafts are hindered, resulting in blockade of TLR4-mediated signaling responses through NF- $\kappa$ B and IRF3 and reduced inflammatory cytokine secretion. These results provide a foundation for the development of therapeutic strategies employing Se to prevent or treat endometritis.

\section{MATERIALS AND METHODS}

\section{Animals and experimental groups}

A total of 60 female C57 mice (2 weeks), weighing 10-15 g, were randomly divided into 3 groups (20 mice per group). Each group was fed a diet containing either a low $(0.015 \mathrm{mg} / \mathrm{kg})$, normal $(0.15 \mathrm{mg} / \mathrm{kg})$ or high $(1.5 \mathrm{mg} / \mathrm{kg}) \mathrm{Se}$ concentration. the water provided to each group was also supplemented without Se. 90 days later, each group of mice was randomly divided into two groups (10 mice per group), one of which was treated with LPS $(20 \mu \mathrm{l}$ LPS $0.05 \mathrm{mg}$ / $\mathrm{ml}$ by intrauterine infusion) and the other (control) was injected with normal saline. After $24 \mathrm{~h}$ of stimulation, all mice were anesthetized and sacrificed, and uterine tissues were collected immediately for further analyses.

All animals were housed in Huazhong Agricultural University and the experiments were performed according to the guidelines published by the Care and Use of Experimental Animals of the National Institutes of Health (USA).

\section{Determination of se concentration in uterine tissues and blood}

Se content in uterine tissues and blood was measured following the method described by YAO et al [26]. Se
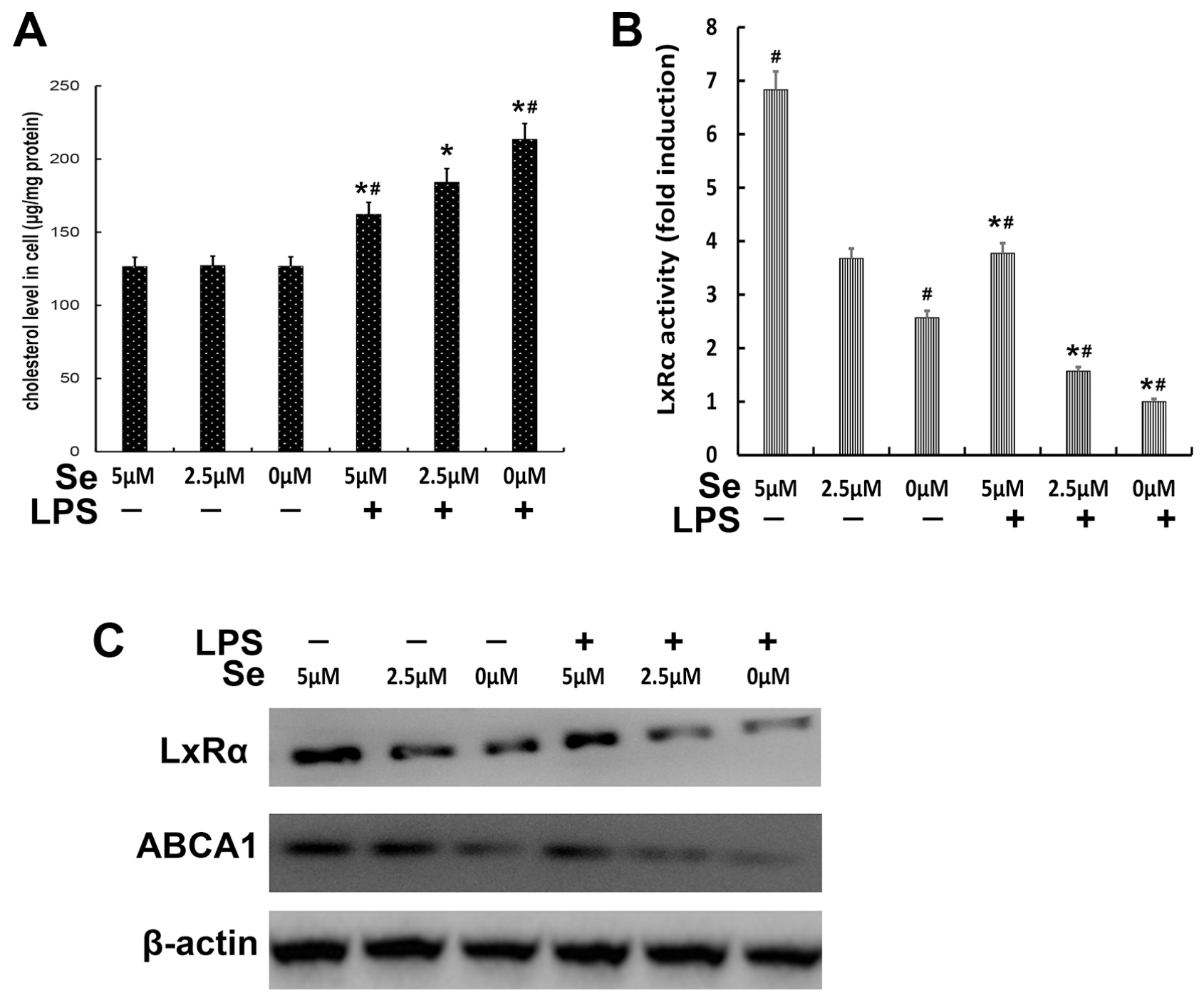

Figure 11: Effects of Se supplementation on cellular cholesterol, $\mathbf{L x R} \boldsymbol{\alpha}$, and ABCA1. (A) Se inhibits LPS-induced cholesterol formation in a dose-dependent manner. Cholesterol levels in cultured cells were determined using a Cholesterol Quantitation Kit. ${ }^{*} p<0.05$, compared with the LPS $+2.5 \mu \mathrm{M}$ Se group; ${ }^{*} p<0.05$, compared with the non-stimulated group. (B) Effect of Se on LxR $\alpha$ activity. The luciferase reporter gene assay was used to investigate the activity of $\operatorname{LxR} \alpha .{ }^{*} p<0.05$, compared to the $2.5 \mu \mathrm{M}$ Se group; ${ }^{*} p<0.05$, compared to the non-stimulated group. (C) Effects of Se on LxR $\alpha$ and ABCA1 expression. LxR $\alpha$ and ABCA1 protein levels were analyzed by western blot with specific antibodies. $\beta$-actin was used as a loading control. 

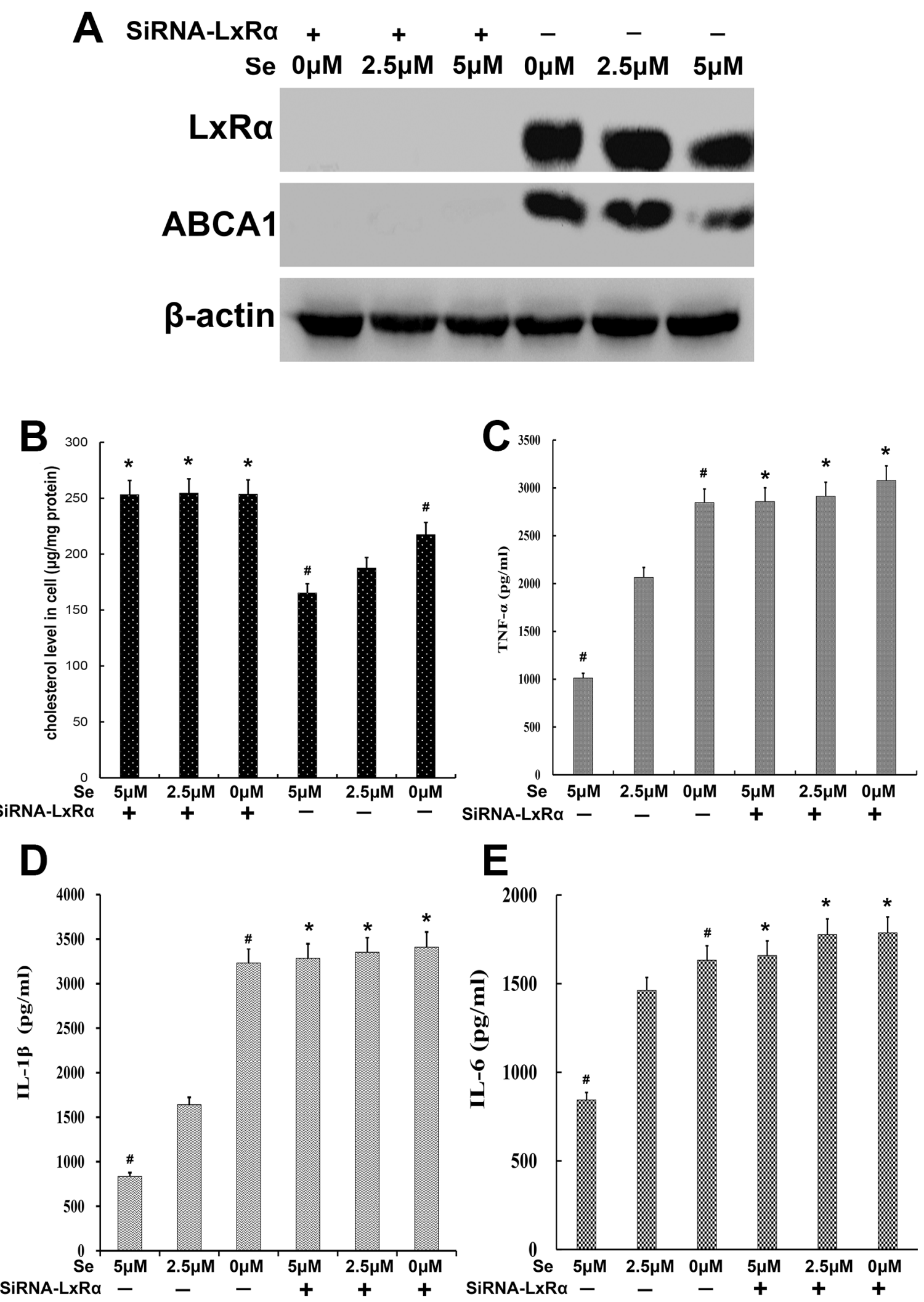

Figure 12: $\operatorname{LxR} \alpha$ knockdown reverses the reductions in both cholesterol levels and LPS-induced inflammatory cytokines mediated by Se. (A) LxR $\alpha$ and ABCA1 expression (assessed by western blot) was significantly suppressed by siRNA-LxR $\alpha$. (B) Effect of siRNA-LxR $\alpha$ on cellular cholesterol levels. (C) Effect of siRNA-LxR $\alpha$ on TNF- $\alpha$ levels, as measured by ELISA. (D) Effect of siRNA-LxR $\alpha$ on IL-1 $\beta$ levels. (E) Effect of siRNA-LxR $\alpha$ on IL-6 levels. Data are presented as means \pm SEM, ${ }^{*} p<0.05$, compared to the $2.5 \mu \mathrm{M}$ group. ${ }^{*} p<0.05$, compared to the LxR $\alpha$-expressing control group. 
contained in the samples was converted to selenite by acid treatment. The reaction of selenic acid with aromatic o-diamine forms 4,5-benzodiazobisenium, which emits a bright lime green fluorescence when excited at $366 \mathrm{~nm}$ in cyclohexane. With excitation and emission wavelengths set at 366 and $520 \mathrm{~nm}$ respectively, the emission of the extracted cyclohexane was measured with a fluorescence spectrophotometer. Results were calculated in reference to a standard curve.

\section{Histological analysis}

Uterine tissues were fixed in a $10 \%$ formaldehyde solution and embedded in paraffin. Sections were

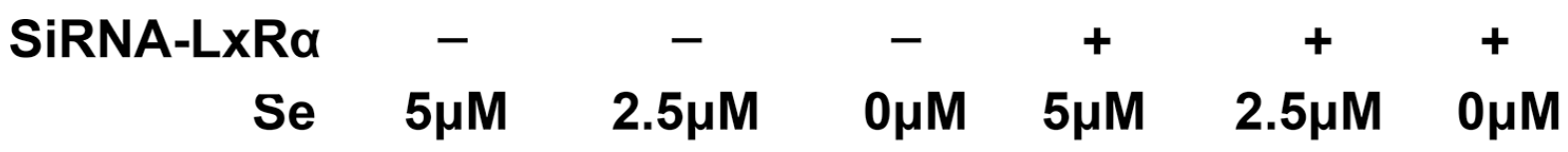

TLR4

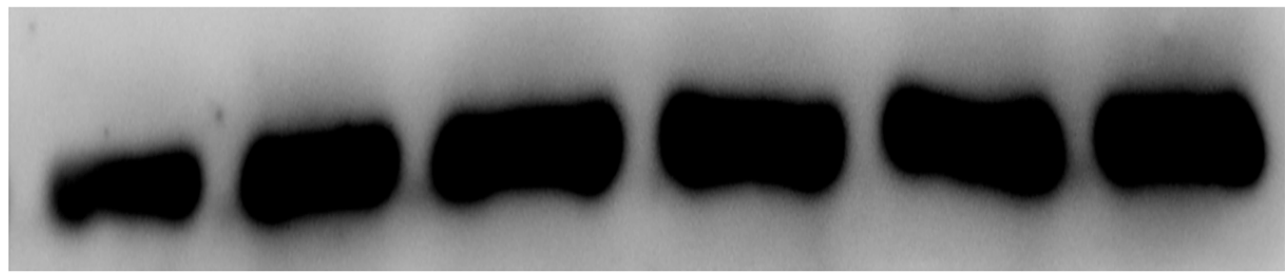

p65

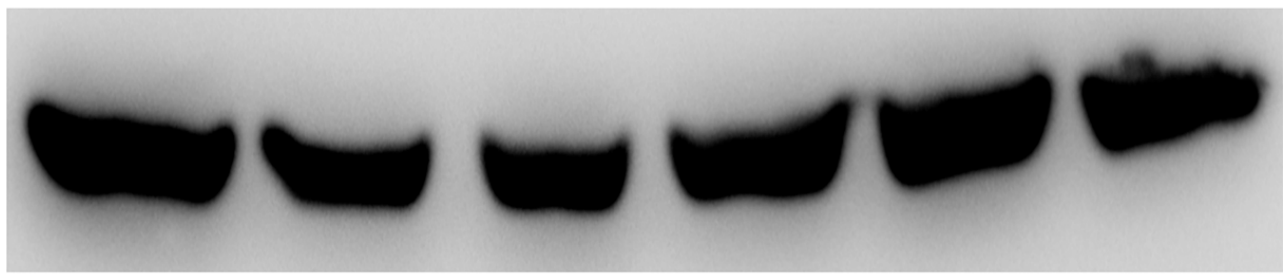

IRF3

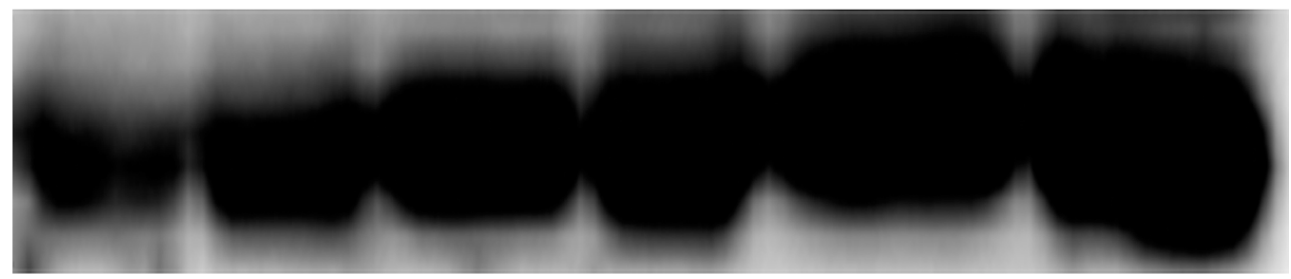

p-p65

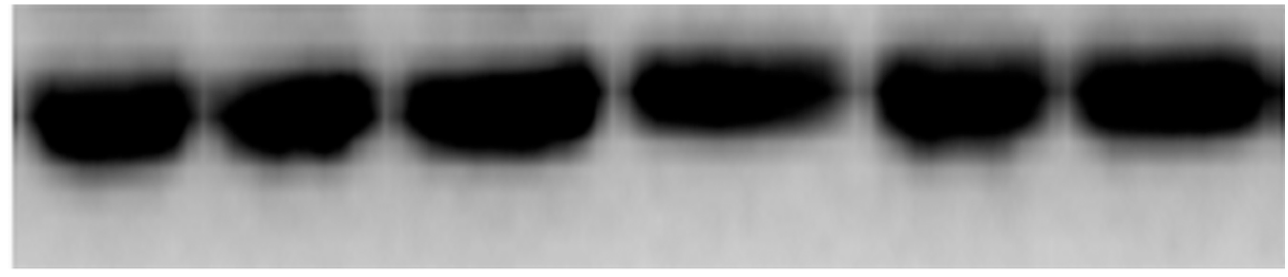

p-IRF3

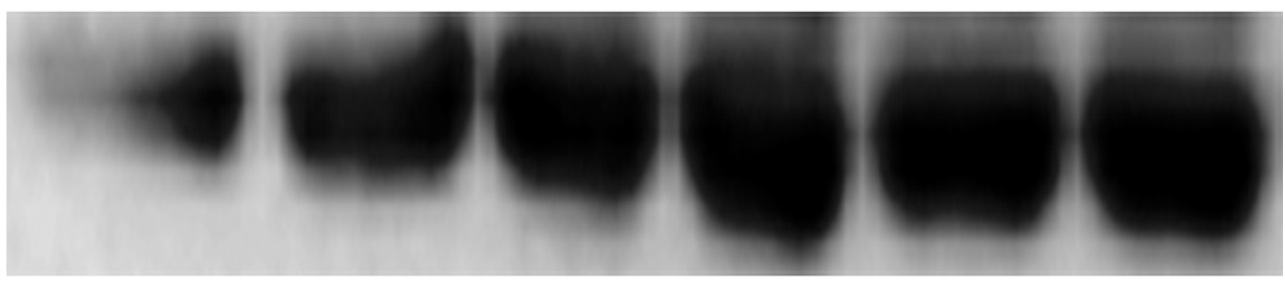

$\beta$-actin

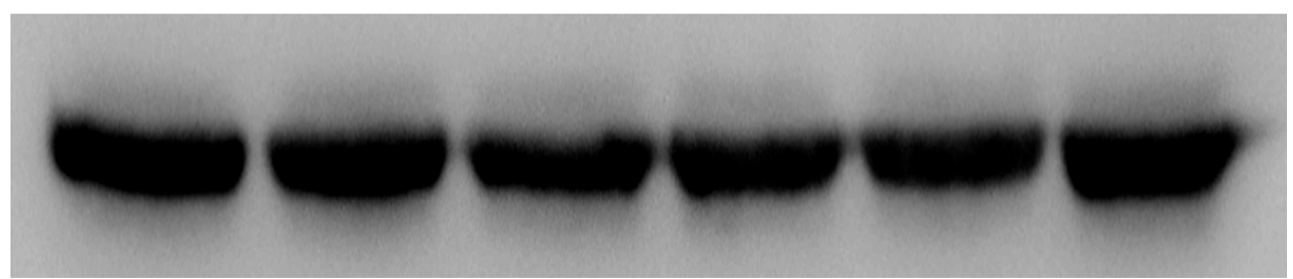

Figure 13: LxR $\alpha$ knockdown reverses Se-mediated reduction in TLR4 signaling proteins. TLR4, NF- $\mathrm{kB}$, and IRF3 protein levels were analyzed by western blot. $\beta$-actin was used as a loading control. 
dewaxed with xylene and rehydrated by fractionated alcohol for hematoxylin and eosin (H \& E) and TUNEL staining.

\section{TUNEL staining}

Tissue sections were treated with proteinase $\mathrm{K}$ and then fixed with paraformaldehyde solution. After being permeabilized in sodium citrate solution, the sections were labeled with the TUNEL reaction mixture use (FITCconjugated anti-BrdU) and analyzed with a fluorescence microscope with an excitation/emission filter set at $530 / 630 \mathrm{~nm}$.

\section{MPO analysis}

The tissues were ground and homogenized. The supernatant was centrifuged and the MPO antibody was coated with 96-well plates with $1 / 100(\mathrm{v} / \mathrm{v})$. After adding the standard and the sample, the anti-MPO antibody and the color reagent were added to the above mixture, and the mixture was treated with a spectrophotometer at $460 \mathrm{~nm}$. The photometric value is measured at the wavelength. All operations follow the manufacturer's instructions (Nanjing Jiancheng Bioengineering Institute, Nanjing, China).

\section{Isolation, culture, and identification of cells}

the endometrium tissues were minced into paste, and then digested, removed undissociated tissues and debris, collected the cells and resuspended in DMEM/ F12 containing $10 \%$ FCS, cleared away fibroblasts, and cultured in DMEM/F12 containing $10 \% \mathrm{FCS}$ at $37^{\circ} \mathrm{C}$ with $5 \% \mathrm{CO}_{2}$. Cells obtained after dissociation of uterine fragments were split into 3 groups and treated with medium containing $0,2.5$ or $5 \mu \mathrm{M} \mathrm{Se}$, respectively. Each group was further divided into two sub-groups, one of which was treated with LPS for $1 \mathrm{~h}$ while the other was incubated in normal saline without LPS. The morphology of the cells was observed under a microscope.

\section{Cell viability}

Cells were collected, washed, and incubated in a 96-well plate for $24 \mathrm{~h} .20 \mathrm{ml}$ of MTT $(5 \mathrm{mg} / \mathrm{ml})$ were then added to each well and the cells were further cultured for 4 h. After removing the supernatant, formazan was dissolved with DMSO. Signal quantitation was performed at $570 \mathrm{~nm}$ using a microplate reader.

\section{Extraction and calibration of lipid rafts}

Uterine samples were weighted, homogenized, and treated with MBS buffer. The resulting cells were collected, washed in cold PBS, and treated with MBS buffer. The lysate was mixed with an equal volume of $80 \%$ sucrose solution and covered with $30 \%$ and $5 \%$ sucrose solutions, then centrifuged at $32,000 \mathrm{rpm}$ for $20 \mathrm{~h}$ at $4^{\circ} \mathrm{C}$. The identification of lipid rafts was performed using a fluorescent cholesterol derivative.

\section{Determination of cholesterol concentration}

Both the colorimetric and fluorometric assays require $50 \mu \mathrm{L}$ of sample for each reaction (well). Tissue $(10 \mathrm{mg})$ or cells $\left(1 \times 10^{6}\right)$ can be extracted. Tissue and cellular cholesterol levels were determined using a Cholesterol Quantitation Kit in accordance with the manufacturer's instructions (Sigma-Aldrich MAK043). $50 \mu \mathrm{L}$ Reaction Mix with each well, and incubate for 60 minutes at $37^{\circ} \mathrm{C}$. Protect the plate from light during the incubation. For colorimetric assays, measure the absorbance at $570 \mathrm{~nm}$ (A570). For fluorometric assays, measure fluorescence intensity $(\lambda \mathrm{ex}=535 / \lambda \mathrm{em}=587 \mathrm{~nm})$.

\section{LxR $\alpha$ RNA interference}

The target sequences were designed for the interference of $\operatorname{LxR} \alpha$ according to the design principle of siRNA. The siRNA sequences were confirmed by BLAST analysis and synthesized by chemical synthesis method. Dilute $2 \mu \mathrm{l}$ siRNA and $1.5 \mu \mathrm{l}$ Lipofectamine2000 with Opti-MEM respectively. Lipofectamine2000 and siRNA blend to join culture plate for $24 \mathrm{~h}$ and uterine smooth muscle cells transfection. The specific target siRNA sequences of $\operatorname{LxR} \alpha$ were used as the siRNA and the control group respectively inoculated in 6-well plates.

\section{ELISA assay}

ELISA kits (BioLegend, Inc., USA) were used to detect TNF- $\alpha$, IL- 6 , and IL-1 $\beta$ in the supernatants of tissue homogenates and cultured cells according to the manufacturer's instructions.

\section{qRT-PCR}

Mice uterine samples were weighed, homogenized, and treated with TRIzol reagent. Cultured cells were collected, washed in cold PBS twice, and treated with TRIzol. After verifying concentration and purity at 260/280 nm using a spectrophotometer, total RNA was reverse-transcribed into cDNA using a commercial kit. The mRNA concentrations of IL- 6 , IL- $1 \beta$, TNF- $\alpha$, TLR4, and $\beta$-actin were quantified using quantitative real-time polymerase chain reaction (qRT-PCR), with each reaction carried out three times.

\section{Western blot}

Proteins $(60 \mathrm{mg})$ from uterine tissue samples and isolated cells were separated by SDS-PAGE using Tris- 
$\mathrm{HCl}$ Precast Gels and transferred onto PVDF membranes. The membranes were blocked in Tris-Tween buffered saline (TBST) supplemented with 5\% skim milk at room temperature for $2 \mathrm{~h}$, followed by TBST washing. Primary antibodies against NF-кB p65, IRF3, TLR4, LxR $\alpha$, ABCA1, and $\beta$-actin (1: 1000 dilution) were incubated overnight at $4^{\circ} \mathrm{C}$. The membrane was washed with TBST and incubated with a 1:5000 dilution of secondary antibody for $1 \mathrm{~h}$ at room temperature. An enhanced chemiluminescence detection system was used to reveal specific binding. $\beta$-actin was used as internal reference for equal protein loading.

\section{Statistical analysis}

SPSS software was used to analyze the data. Differences between the mean values of normally distributed data were evaluated with one-way ANOVA and then analyzed by Tukey-Kramer post-analysis test. The $p$ values $<0.05$ was set as the threshold for significance.

\section{ACKNOWLEDGMENTS AND FUNDING}

This work was supported by grants from the National Natural Science Foundation of China (NO. 31502130) and the Fundamental Research Funds for the Central Universities (No. 2662014BQ024).

\section{CONFLICTS OF INTEREST}

There are no conflicts of interest to declare.

\section{REFERENCES}

1. Zhang Z, Gao X, Cao Y, Jiang H, Wang T, Song X, Guo M, Zhang N. Selenium Deficiency Facilitates Inflammation Through the Regulation of TLR4 and TLR4-Related Signaling Pathways in the Mice Uterus. Inflammation. 2015; 38:1347-56. https://doi.org/10.1007/s10753-014-0106-9.

2. Williams EJ, Fischer DP, Pfeiffer DU, England GC, Noakes DE, Dobson H, Sheldon IM. Clinical evaluation of postpartum vaginal mucus reflects uterine bacterial infection and the immune response in cattle. Theriogenology. 2005; 63:102-17. https://doi.org/10.1016/j. theriogenology.2004.03.017.

3. Werner A, Suthar V, Plöntzke J, Heuwieser W. Relationship between bacteriological findings in the second and fourth weeks postpartum and uterine infection in dairy cows considering bacteriological results. J Dairy Sci. 2012; 95:7105-14. https://doi.org/10.3168/jds.2012-5627.

4. Hu Y, Wang Z, Pan S, Zhang H, Fang M, Jiang H, Zhang H, Gao Z, Xu K, Li Z, Xiao J, Lin Z. Melatonin protects against blood-brain barrier damage by inhibiting the TLR4/ NF- $\kappa \mathrm{B}$ signaling pathway after LPS treatment in neonatal rats. Oncotarget. 2017; 8:31638-54. https://doi. org/10.18632/oncotarget.15780.
5. Wei Z, Wang J, Shi M, Liu W, Yang Z, Fu Y. Saikosaponin a inhibits LPS-induced inflammatory response by inducing liver $\mathrm{X}$ receptor alpha activation in primary mouse macrophages. Oncotarget. 2016; 7:48995-9007. https://doi. org/10.18632/oncotarget.9863.

6. Murai T. Lipid Raft-Mediated Regulation of HyaluronanCD44 Interactions in Inflammation and Cancer. Front Immunol. 2015; 6:420. https://doi.org/10.3389/ fimmu.2015.00420.

7. Xu Y, Yang B, Hu Y, Lu L, Lu X, Wang J, Xu F, Yu S, Huang J, Liang X. Wogonin prevents TLR4-NF- $\kappa \mathrm{B}-$ medicated neuro-inflammation and improves retinal ganglion cells survival in retina after optic nerve crush. Oncotarget. 2016; 7:72503-17. https://doi.org/10.18632/oncotarget.12700.

8. Yang T, Zhao Z, Liu T, Zhang Z, Wang P, Xu S, Lei XG, Shan A. Oxidative stress induced by Se-deficient highenergy diet implicates neutrophil dysfunction via Nrf2 pathway suppression in swine. Oncotarget. 2017; 8:1342839. https://doi.org/10.18632/oncotarget.14550.

9. Cao C, Fan R, Zhao J, Zhao X, Yang J, Zhang Z, Xu $\mathrm{S}$. Impact of exudative diathesis induced by selenium deficiency on LncRNAs and their roles in the oxidative reduction process in broiler chick veins. Oncotarget. 2017; 8:20695-705. https://doi.org/10.18632/oncotarget.14971.

10. Li JL, Li W, Sun XT, Xia J, Li XN, Lin J, Zhang C, Sun $\mathrm{XC}, \mathrm{Xu} \mathrm{SW}$. Selenophosphate synthetase 1 (SPS1) is required for the development and selenium homeostasis of central nervous system in chicken (Gallus gallus). Oncotarget. 2017; 8:35919-32. https://doi.org/10.18632/ oncotarget.16283.

11. Guo M, Gao X, Zhang N, Qiu C, Li C, Deng G. Effects of Se on the Diversity of SelT Synthesis and Distribution in Different Smooth Muscle Tissues in Rats. Biol Trace Elem Res. 2016; 170:340-7. https://doi.org/10.1007/s12011-0150444-y.

12. Yao HD, Wu Q, Zhang ZW, Zhang JL, Li S, Huang JQ, Ren FZ, Xu SW, Wang XL, Lei XG. Gene expression of endoplasmic reticulum resident selenoproteins correlates with apoptosis in various muscles of se-deficient chicks. J Nutr. 2013; 143:613-9. https://doi.org/10.3945/ jn.112.172395.

13. Roth S, Zhang S, Chiu J, Wirth EK, Schweizer U. Development of a serum-free supplement for primary neuron culture reveals the interplay of selenium and vitamin E in neuronal survival. J Trace Elem Med Biol. 2010; 24:130-7. https://doi.org/10.1016/j.jtemb.2010.01.007.

14. Mistry HD, Broughton Pipkin F, Redman CW, Poston L. Selenium in reproductive health. Am J Obstet Gynecol. 2012; 206:21-30. https://doi.org/10.1016/j. ajog.2011.07.034.

15. Yao H, Fan R, Zhao X, Zhao W, Liu W, Yang J, Sattar H, Zhao J, Zhang Z, Xu S. Selenoprotein W redox-regulated $\mathrm{Ca} 2+$ channels correlate with selenium deficiency-induced muscles Ca2+ leak. Oncotarget. 2016; 7:57618-32. https:// doi.org/10.18632/oncotarget.11459. 
16. Roman M, Jitaru P, Barbante C. Selenium biochemistry and its role for human health. Metallomics. 2014; 6:25-54. https://doi.org/10.1039/c3mt00185g.

17. Nakahira K, Kim HP, Geng XH, Nakao A, Wang X, Murase N, Drain PF, Wang X, Sasidhar M, Nabel EG, Takahashi T, Lukacs NW, Ryter SW, et al. Carbon monoxide differentially inhibits TLR signaling pathways by regulating ROS-induced trafficking of TLRs to lipid rafts. J Exp Med. 2006; 203:2377-89. https://doi.org/10.1084/jem.20060845.

18. Muppidi JR, Tschopp J, Siegel RM. Life and death decisions: secondary complexes and lipid rafts in TNF receptor family signal transduction. Immunity. 2004; 21:461-65. https://doi.org/10.1016/j.immuni.2004.10.001.

19. Rayman MP, Stranges S, Griffin BA, Pastor-Barriuso R, Guallar E. Effect of supplementation with high-selenium yeast on plasma lipids: a randomized trial. Ann Intern Med. 2011; 154:656-65. https://doi.org/10.7326/0003-4819-15410-201105170-00005.

20. Wolf NM, Mueller K, Hirche F, Most E, Pallauf J, Mueller AS. Study of molecular targets influencing homocysteine and cholesterol metabolism in growing rats by manipulation of dietary selenium and methionine concentrations. Br J Nutr. 2010; 104:520-32. https://doi.org/10.1017/ S0007114510000899.

21. Kagan JC, Medzhitov R. Phosphoinositide-mediated adaptor recruitment controls Toll-like receptor signaling.
Cell. 2006; 125:943-55. https://doi.org/10.1016/j. cell.2006.03.047.

22. Lu YC, Yeh WC, Ohashi PS. LPS/TLR4 signal transduction pathway. Cytokine. 2008; 42:145-51. https://doi. org/10.1016/j.cyto.2008.01.006.

23. Olsson S, Sundler R. The role of lipid rafts in LPS-induced signaling in a macrophage cell line. Mol Immunol. 2006; 43:607-12. https://doi.org/10.1016/j.molimm.2005.04.011.

24. Zhu J, Zhang X, Chen X, Sun Y, Dai Y, Chen C, Zhang T, Yan Z. Studies on the regulation of lipid metabolism and the mechanism of the aqueous and ethanol extracts of Usnea. Biomed Pharmacother. 2017; 94:930-936. https:// doi.org/10.1016/j.biopha.2017.08.012.

25. Zhu X, Owen JS, Wilson MD, Li H, Griffiths GL, Thomas MJ, Hiltbold EM, Fessler MB, Parks JS. Macrophage ABCA1 reduces MyD88-dependent Toll-like receptor trafficking to lipid rafts by reduction of lipid raft cholesterol. J Lipid Res. 2010; 51:3196-206. https://doi.org/10.1194/jlr. M006486.

26. Yao HD, Wu Q, Zhang ZW, Li S, Wang XL, Lei XG, Xu SW. Selenoprotein W serves as an antioxidant in chicken myoblasts. Biochim Biophys Acta. 2013; 1830:3112-20. https://doi.org/10.1016/j.bbagen.2013.01.007. 